\title{
Interspinous process device versus standard conventional surgical decompression for lumbar spinal stenosis: randomized controlled trial
}

\author{
Wouter A Moojen neurosurgery resident and epidemiologist ${ }^{12}$, Mark P Arts neurosurgeon ${ }^{2}$, Wilco \\ $\mathrm{C} \mathrm{H}$ Jacobs epidemiologist ${ }^{1}$, Erik W van Zwet statistician ${ }^{3}$, M Elske van den Akker-van Marle health \\ economist ${ }^{4}$, Bart W Koes epidemiologist ${ }^{5}$, Carmen L A M Vleggeert-Lankamp neurosurgeon ${ }^{1}$, Wilco \\ C Peul neurosurgeon and epidemiologist ${ }^{12}$, for the Leiden-The Hague Spine Intervention Prognostic \\ Study Group (SIPS)
}

'Department of Neurosurgery, Leiden University Medical Center, Leiden, Netherlands; ${ }^{2}$ Department of Neurosurgery, Medical Center Haaglanden, The Hague, Netherlands; ${ }^{3}$ Department of Medical Statistics and Bioinformatics, Leiden University Medical Center; ${ }^{4}$ Department of Medical Decision Making, Leiden University Medical Center; ${ }^{5}$ Department of General Practice, Erasmus Medical Center, Rotterdam, Netherlands

\begin{abstract}
Objective To assess whether interspinous process device implantation is more effective in the short term than conventional surgical decompression for patients with intermittent neurogenic claudication due to lumbar spinal stenosis.

Design Randomized controlled trial.

Setting Five neurosurgical centers (including one academic and four secondary level care centers) in the Netherlands.

Participants 203 participants were referred to the Leiden-The Hague Spine Prognostic Study Group between October 2008 and September 2011; 159 participants with intermittent neurogenic claudication due to lumbar spinal stenosis at one or two levels with an indication for surgery were randomized.
\end{abstract}

Interventions 80 participants received an interspinous process device and 79 participants underwent spinal bony decompression.

Main outcome measures The primary outcome at short term (eight weeks) and long term (one year) follow-up was the Zurich Claudication Questionnaire score. Repeated measurements were made to compare outcomes over time.

Results At eight weeks, the success rate according to the Zurich Claudication Questionnaire for the interspinous process device group (63\%, 95\% confidence interval $51 \%$ to $73 \%$ ) was not superior to that for standard bony decompression (72\%, $60 \%$ to $81 \%)$. No differences in disability (Zurich Claudication Questionnaire; $\mathrm{P}=0.44$ ) or other outcomes were observed between groups during the first year. The repeat surgery rate in the interspinous implant group was substantially higher $(n=21$;
$29 \%)$ than that in the conventional group $(n=6 ; 8 \%)$ in the early post-surgical period $(\mathrm{P}<0.001)$.

Conclusions This double blinded study could not confirm the hypothesized short term advantage of interspinous process device over conventional "simple" decompression and even showed a fairly high reoperation rate after interspinous process device implantation.

Trial registration Dutch Trial Register NTR1307.

\section{Introduction}

Recent developments in spinal surgery implants promise less invasive procedures with superior effectiveness to conventional surgery. ${ }^{1}$ Particularly in (older) patients with spinal stenosis due to arthrosis of the facet joints, implantation of an interspinous process device is regularly offered. However, the growing incidence of low back surgery with additional implants for degenerative spine disease has raised questions from the scientific community. ${ }^{2}$ Furthermore, the economic burden of management of lumbar spine disorders (lumbar spinal disorder and lumbar disc disease combined) was already worrisome in the 1990s, when they ranked fifth on the basis of cost of hospital care. ${ }^{4}$ The increasing use of implants, combined with a growing older population, leads to societal concerns as the cost of the management of spinal stenosis is escalating. ${ }^{56}$

Lumbar degenerative spinal stenosis is caused by arthrosis of the facet joints and development stenosis, which can result in lumbar nerve root compression. ${ }^{7}$ As in other acquired diseases, intermittent neurogenic claudication is usually seen in older 
people. ${ }^{8}$ Severe stenosis is common in older people's spines: $30.4 \%$ of the Japanese population had a severe stenosis (average age 67.3 (range $40-93$ ) years). ${ }^{9}$ Why only $17.5 \%$ of these patients have typical symptoms is not yet known. Most of these patients complain of a complex of symptoms, described as leg pain (frequently in both legs), which is exacerbated by walking, prolonged standing, or lumbar extension. ${ }^{7-11}$ Classically, the cramp, tightness, pain, or discomfort in the legs will diminish after a short period of sitting or bending forward. ${ }^{8}$ Apart from the leg pain, associated low back pain may occur. ${ }^{12}$ The optimum treatment of lumbar spinal stenosis is generally considered to be surgical intervention, as two randomized clinical trials comparing conservative treatment with conventional bony decompression resulted in treatment effects in favor of surgery. ${ }^{1314}$ The treatment outcome falls short of surgeons' expectations, as surgical decompression yields a modest outcome, being favorable in only $65 \%$ of patients. ${ }^{13-17}$ This slightly disappointing success rate is said to be due to the destructive nature of bony decompressive surgery of the spinal column. ${ }^{18}{ }^{19}$ Instability of the lumbar spine follows laminectomy, requiring subsequent instrumental spondylodesis. ${ }^{2021}$ Spinal surgeons and the medical device industry are therefore looking for a less detrimental alternative in the surgical care for the older population.

Minimally invasive surgery has gained popularity in recent years, resulting in the development of various interspinous process devices. ${ }^{22}$ The interspinous process device was developed to stabilize and increase the interspinous distance with indirect decompression of the dural sac and nerve roots. ${ }^{23-33}$ Treatment of neurogenic claudication with has been shown to be superior to conservative care. ${ }^{34-36}$ The Coflex implant (Paradigm Spine, USA) was developed as a second generation interspinous process device to give indirect decompression with the possibility of stabilizing the lumbar spine after bony decompression. Although some medical societies in Western countries believe in additional pedicle screw fixation of the lumbar spine, the scientific gold standard of surgical treatment of lumbar spinal stenosis is bony decompression. ${ }^{37}{ }^{38}$ All new surgical techniques to treat lumbar spinal stenosis should be compared with this technique. ${ }^{13-39}$ Although society might be subjected to media driven medicine and early adoption of surgical implants, the spinal scientific community believes that well designed comparative studies should be conducted before a new implant can replace the gold standard. Interspinous process devices have been suggested to have better short term (eight weeks) recovery than and similar long term (cost) effectiveness to bony decompression. ${ }^{23-41}$ The purpose of this study was to assess whether interspinous process device implantation is more effective in the short term than conventional surgical decompression for patients with intermittent neurogenic claudication due to lumbar spinal stenosis.

\section{Methods}

We did a prospective, randomized, double blind, multicenter trial among patients with intermittent neurogenic claudication due to lumbar spinal stenosis after failed conservative treatment (Foraminal Enlargement Lumbar Interspinosus distraXion: FELIX trial). We compared minimally invasive treatment with interspinous process devices against usual care (conventional bony decompression). The design and study protocol have been published previously. ${ }^{42}$

\section{Eligibility and randomization}

Patients aged between 40 and 85 years with at least three months of intermittent neurogenic claudication due to single or two level degenerative lumbar canal stenosis and an indication for surgery were eligible. All patients were diagnosed as having intermittent neurogenic claudication by a neurologist in one of the participating hospitals. If magnetic resonance imaging showed a lumbar spinal canal stenosis, the consulting neurosurgeon could include patients as surgical candidates for the study. At the time of enrollment, an independent research nurse verified the persistence of the symptoms. We excluded patients with a cauda equina syndrome, a herniated disc needing discectomy, history of lumbar surgery, or significant scoliosis (Cobb angle $>25^{\circ}$ ) or other spinal deformities.

We used a randomized design with variable block sizes, with allocations stratified according to center. Allocations were stored in prepared opaque, coded, and sealed envelopes. The key was accessible only to the ProMISe data management system of the Department of Medical Statistics and BioInformatics of the Leiden University Medical Center. All patients gave informed consent. After induction of anesthesia, the prepared envelope was opened and the patient allocated to one of the treatment arms. Patients, nurses on the hospital wards, and research nurses remained blind to the allocated treatment during the follow-up period of one year. The surgical report was kept separately from the patient's regular clinical forms and was available to the neurosurgeon only in case of complications or reoperations.

\section{Interventions}

Patients allocated to the experimental group were operated on under general anesthesia in the knee-elbow position; no bony decompression was done, and an interspinous process device was implanted by a posterior midline approach using radiographic data for localization of the appropriate level. Patients in the standard bony decompression group had surgery in the same knee-elbow position done using a similar incision length to the interspinous process device group to keep all caregivers blind to the allocated treatment. A partial resection of the adjacent laminas was executed, followed by a flavectomy with bilateral opening of the lateral recess. If judged necessary, a medial facetectomy was done. Patients in both groups received the same standard postoperative care. Patients and the research nurses who were following them were asked after every visit if they were still blind to the allocated treatment. ${ }^{42}$

\section{Outcomes}

The primary outcome measure was a disorder specific functional score, obtained by the Zurich Claudication Questionnaire. ${ }^{43-45}$ The primary outcome score was assessed at baseline and at 2 , $4,8,12,26$, and 52 weeks after surgery. The questionnaire consists of three domains (symptom severity, physical function, and patients' satisfaction), in which respectively seven, five, and six questions are answered on a five point (symptom severity) or a four point (physical function and patients' satisfaction) scale. The subscale scores were the averages of the points obtained for every question of the subscale, with a maximum score of 5 for symptom severity and 4 for physical function and patients' satisfaction. The score increases with increasing disability. Blinded research nurses obtained the average subscale scores at every follow-up visit. ${ }^{42} \mathrm{We}$ considered the overall Zurich Claudication Questionnaire score to represent a "successful recovery" when at least two domain subscales were judged as "success." ${ }^{46}$ We defined "success" on the symptom severity scale and on the physical function scale as a 
decrease of at least 0.5 points; a score of less than 2.5 on the patients' satisfaction subscale represented "success." 444

Secondary outcome measures were the modified Roland Disability Questionnaire for sciatica (scores range from 0 to 23, with higher scores indicating worse functional status), ${ }^{47-55}$ a 100 $\mathrm{mm}$ visual analogue scale for back and leg pain (with 0 representing no pain and 100 the worst pain ever experienced), ${ }^{56}$ the Medical Outcomes Study 36 item Short Form Generated Health Survey (SF-36) scale (based on eight scaled scores, which are the weighted sums in their sections), ${ }^{57}{ }^{58}$ the McGill Pain Questionnaire (with 0 representing minimum pain score and 78 maximum pain score), ${ }^{59}$ and a seven point Likert-type self rating scale of global perceived recovery as assessed by the question of whether the patient had experienced recovery (dichotomized into 1-2 for recovery and 3-7 for no recovery). ${ }^{61}$ Furthermore, patients underwent a shuttle walking test with a predefined maximum distance and timeframe (1200 $\mathrm{m}$ or 15 min). ${ }^{62}$ Patients were scored as "success" when they walked $1200 \mathrm{~m}$ within 15 minutes or showed an increase of more than $80 \mathrm{~m}$ compared with their baseline walking distance. ${ }^{42-64}$ Finally, we used a Hospital Anxiety and Depression Scale consisting of a seven item depression scale and a seven item anxiety scale (4 point scale from 0 to 3$){ }^{65}$ The seven items of the depression scale are related (if more than 8 points) to depression, and the seven items of the anxiety scale are related (if more than 8 points) to generalized anxiety disorder. ${ }^{66}$ Most studies report a cut-off point at 8 points. We assessed secondary outcome scores at baseline and at two (only visual analogue scale back and leg pain), eight 12, 26, and 52 weeks. The Hospital Anxiety and Depression Scale anxiety and depression scores were obtained at baseline and after 52 weeks.

\section{Sample size}

The aim of this study was to assess whether the experimental surgical technique with an interspinous process device would be superior to conventional surgery for patients with intermittent neurogenic claudication due to lumbar spinal stenosis on short term outcome scales. Based on our main outcome score (Zurich Claudication Questionnaire) and an assumed minimal clinically important change of $20 \%$ difference in the overall success rate between the two groups at eight weeks and $10 \%$ loss to follow-up, we calculated that a sample size of 80 patients in each treatment group would be required to provide a statistical power of 0.80 and a two sided $\alpha$ of $0.05 .{ }^{43-46} \mathrm{We}$ determined this $20 \%$ success rate on the basis of the assumption that superiority would be convincing enough to change the surgical guidelines. Researchers had access to the data only after the full follow-up period of one year.

\section{Statistical analysis}

We compared groups on the basis of an intention to treat analysis. We analyzed differences between groups at all the follow-up $(2,4,8,12,26$, and 52 weeks) time points with repeated measurement analysis. To account for the correlation between repeated measurements of the same person, we used generalized estimating equations. We present the difference between the results for the two groups as an odds ratio for binary outcome variables and as mean differences for continuous outcome variables. ${ }^{42}$ To investigate potential bias due to loss to follow-up, we did a sensitivity analysis for the primary outcome by assigning a poor outcome to all missing cases.

At randomization, the administrative center stratified the study for the purpose of analyzing possible heterogeneity among centers and attempting a clinical interpretation of such heterogeneity. We tested heterogeneity between centers by using center as a covariate in the mixed model. We combined those centers that were referring patients to the same hospital and the same surgeon for treatment. Hence, for the analysis of heterogeneity, a center means the actual location where the treatment (according to random allocation) took place. We used the ProMISe data management system of the Department of Medical Statistics and BioInformatics of the Leiden University Medical Center Data for collection of data and checking for quality. We used IBM SPSS software, version 20.0, for all statistical analysis.

\section{Results}

Between October 2008 and September 2011, 203 patients with intermittent neurogenic claudication due to spinal stenosis were referred to the Leiden-The Hague Spine Prognostic Study Group. For all patients, the including neurosurgeon confirmed a single or two level, magnetic resonance imaging confirmed, degenerative stenosis and intermittent neurogenic claudication according to the referring neurologists. One hundred and sixty two patients gave informed consent and were enrolled in the FELIX trial (fig $1 \Downarrow$ ). One patient died while waiting for the operation. Two patients were found to have a severe spondylolysis of the L5-S1 segment at the final preoperative check-up and were excluded from the study, because this could cause a detrimental effect in the implant group. The remaining patients were randomly assigned to interspinous process device or decompression, and 159 patients received the allocated treatment. All patients had had intermittent neurogenic claudication for an average period of 23 (intermittent neurogenic claudication group) and 22 (decompression group) months. No significant differences were noted in baseline characteristics between patients in the two treatment arms (table $1 \Downarrow$ ). Seven patients were lost to follow-up in the interspinous process device group and one patient in the bony decompression group.

Successful recovery according to the Zurich Claudication Questionnaire at short term follow-up (eight weeks) was achieved by $63 \%$ of the patients in the interspinous process device group compared with $72 \%$ in the bony decompression group (odds ratio 0.73; $\mathrm{P}=0.44$. Long term (one year) successful recovery according to the Zurich Claudication Questionnaire was similar in the two groups, resulting in $66 \%$ good results in the interspinous process device group and $69 \%$ in the bony decompression group (odds ratio 0.90; $\mathrm{P}=0.77$ ). Overall, the Zurich Claudication Questionnaire analysis showed no differences between the two treatment arms (table $2 \Downarrow$; fig $2 \Downarrow$ ).

Modified Roland Disability Questionnaire values at eight weeks recovered by a mean score of 7.5 for patients treated with interspinous process device and by a mean score of 6.5 for those treated with bony decompression $(\mathrm{P}=0.28)$. Generalized estimating equations analysis showed no differences between the two treatment arms (table $2 \Downarrow$; fig $2 \Downarrow$ ). Analysis of all other subscales—visual analogue scale back pain $(\mathrm{P}=0.09)$, visual analogue scale leg pain $(\mathrm{P}=0.54)$, McGill Pain Questionnaire $(\mathrm{P}=0.70)$, and Likert scale for perceived recovery $(\mathrm{P}=0.37)$ — showed no differences during the complete follow-up (table $2 \Downarrow$; fig $2 \Downarrow$ ). We found no statistically significant difference in walking distance in the shuttle walking test at eight weeks (odds ratio $0.75 ; \mathrm{P}=0.33$ ) and 52 weeks $(1.25 ; \mathrm{P}=0.54)$ between the two treatment groups. Generalized estimating equations analysis on visual analogue scale back pain and leg pain, SF-36, McGill Pain Questionnaire, Likert score for perceived recovery, shuttle walking test, and Hospital Anxiety and Depression Scale scores also showed no differences (tables $2 \Downarrow$ and $3 \Downarrow$ ). We did 
not adjust primary outcome scores for Hospital Anxiety and Depression Scale depression because of the small percentage of participants with a score of 8 or more (indicating depression). Surgery time (24 min) was shorter in the interspinous process device group than for bony decompression $(43 \mathrm{~min})(\mathrm{P}<0.001)$. Blood loss was less in the interspinous process device group $(10-50 \mathrm{~mL})$ than in the bony decompression group $(50-100 \mathrm{~mL})$ $(\mathrm{P}<0.001)$. Five direct (that is, during the initial hospital stay) postoperative complications occurred in the interspinous process device: one patient with short term (48 hours) unexplained visual disturbance, one patient with self limiting pseudoradicular pain in the other leg, and three patients with interspinous process fractures during interspinous process device placement (table $3 \Downarrow$ ). Direct postoperative complications occurred in six patients in the bony decompression group: two patients with direct epidural hematoma needing reoperation and four patients with dural tears without further consequences. Late reoperation due to absence of recovery was indicated and performed in 21/73 (29\%) cases in the interspinous process device group compared with $6 / 72(8 \%)$ in the bony decompression group $(\mathrm{P}<0.001)$. Of patients who initially received an interspinous process device and were reoperated (explantation of the device and subsequent bony decompression), $48 \%$ scored successful recovery on the Zurich Claudication Questionnaire; of patients in the bony decompression group who were reoperated, $50 \%$ scored successful recovery. The Zurich Claudication Questionnaire outcome of the patients reoperated after interspinous process device placement did not differ significantly from that of the other patients $(\mathrm{P}=0.08)$. Average hospital stay was similar in both groups: 1.83 days for the interspinous process device group and 1.89 days for the bony decompression group $(\mathrm{P}=0.753)$.

Patients were successfully blinded to the treatment chosen in $67 \%$ of the IPD group and $86 \%$ of the standard decompression group.

We did a sensitivity analysis to assess the effect of the missing values for our primary outcome. Firstly, we replaced all missing values with unfavorable outcomes. This did not affect our results in any substantial way. Next, we replaced all missing values with favorable outcomes. Again, we saw no substantial changes to our results. The results for the primary outcome were therefore not sensitive to loss to follow-up.

Thirty seven patients were operated on at two levels (tables $1 \Downarrow$ and $3 \Downarrow$ ). The subgroup of patients with lumbar spinal stenosis operated on at two levels with an interspinous process device (21 patients) had a similar outcome on the Zurich Claudication Questionnaire scale at eight weeks (odds ratio 2.5; $\mathrm{P}=0.06$ ) and at one year $(0.83 ; \mathrm{P}=0.83)$ to those allocated to the bony decompression group (18 patients). Generalized estimating equations analysis showed no difference in Zurich Claudication Questionnaire results between one and two levels of surgery $(\mathrm{P}=0.44)$. However, the reoperation rate of $38 \%$ (eight patients) in the interspinous process device group at two levels was higher than the reoperation rate in the bony decompression group of $6 \%$ (one patient) $(\mathrm{P}<0.05)$.

We found no clinically significant heterogeneity in the outcomes between the five centers (supplementary appendix). The small difference supports the contention that the sample of hospitals is a good representation of the Dutch healthcare system.

\section{Discussion}

Implantation of an interspinous process device as definite treatment for lumbar spinal stenosis did not show the hypothesized short term superior effect over standard bony decompressive surgery. The one year follow-up results of both surgical procedures did not differ, although the reoperation rate for the interspinous process device was significantly higher than that for conventional bony decompression. Another study started in 2007 was terminated when an interim analysis showed a fourfold higher reoperation rate in the interspinous process device group. ${ }^{67}$ The shorter operation time was the only beneficial parameter for patients in the interspinous process device group compared with the bony decompression group, but this did not result in a shorter hospital stay. Furthermore, patients operated on at two levels had an even higher reoperation rate compared with bony decompression. The absence of short term added value of the interspinous process device and the much higher reoperation rate in this study do not allow this new procedure to replace the golden standard of simple bony decompression as treatment for lumbar spinal stenosis.

\section{Strengths and limitations of study}

One of the strengths of this study is that this is the first and only blinded randomized study on this subject. Furthermore, by anomyzation during data analysis, we excluded bias as much as possible. However, the study has also features that may limit the generalizability of its findings. Firstly, selection bias could have been introduced through the opinion of the including neurosurgeon that patients with severe spinal stenosis on magnetic resonance imaging should not be offered an interspinous process device and were thus not included in the FELIX trial. However, clinical features of the patients included in this study showed baseline values (mean visual analogue scale (leg and/or back) of $60 \mathrm{~mm}$ at baseline) comparable to those of other large trials. ${ }^{13}{ }^{14}$ Trials in general tend to include standard patients, but, as mentioned earlier, not all patients with stenosis have clinical complaints, which could lead to potential bias that may limit the generalizability. The number of reoperations in the interspinous process device treatment arm is very worrisome, especially because reoperations do not reach the success rate of primary surgeries; use of interspinous process devices might even prevent recovery in $20 \%$ of patients. Lastly, shuttle walking tests are believed to be the most objective parameter to classify the disease specific complaints of lumbar spinal stenosis. As in many other studies, however, using this test for an older population is often difficult. ${ }^{13}$ Further research should focus on finding a new objective parameter to evaluate the increasingly older population with lumbar spinal stenosis.

\section{Comparison with other studies}

Others researchers have tested the interspinous process device as an alternative for posterior and intercorporal fusion in patients with lumbar spinal stenosis. ${ }^{68}{ }^{69}$ In Dutch practice, instrumental spondylodesis is not a standard adjuvant in spinal stenosis surgery, and nor is it standard in the modern literature. ${ }^{35-42}$ Nevertheless, two studies compared a wide laminectomy combined with interspinous process device placement against treatment with wide laminectomy combined with posterior and intercorporal fusion. ${ }^{68}{ }^{69}$ Both studies concluded that adjuvant interspinous process device treatment is as effective as lumbar $360^{\circ}$ instrumentation in resolving neurogenic claudication. In addition, a non-randomized study had already shown that patients with intermittent neurogenic claudication treated with bony decompression alone had the same long term satisfactory outcome as did patients treated with bony decompression and adjuvant interspinous process device placement. ${ }^{70}{ }^{71}$ Furthermore, a recent smaller non-blinded study reported similar results to those presented here. The clinical outcome of patients treated with an interspinous process device was not superior to that in patients treated with bony decompression. As in our study, 
patients had a higher rate $(26 \% v 6 \%)$ of reoperation in the interspinous process device group. ${ }^{72}$ All studies, including our trial, found no differences between groups with regard to postoperative visual analogue scale leg and back pain. ${ }^{68} 69$ The results of this study and previous studies lead to the overall conclusion that intermittent neurogenic claudication treated with decompression alone results in a comparable outcome compared with treatment with interspinous process device alone, interspinous process device combined with bony decompression, and $360^{\circ}$ instrumented spondylodesis. As instrumented surgery requires more from society and patients, the gold standard for intermittent neurogenic claudication treatment remains the classic bony decompression.

\section{Conclusions}

The hypothesized short term superior effect of treatment with interspinous process device over simple standard surgery was not confirmed by this double blind study. In contrast, treatment with interspinous process devices resulted in a higher reoperation rate and thus prevented a better recovery owing to the lower recovery rate after a second operation. As a spinal research group, we would not recommend the interspinous process device, considering the higher reoperation rate without a short term advantage and most likely with higher costs (interspinous process devices cost at least $€ 2000$ (£1704; \$2756)). We doubt if reimbursement of interspinous process devices by society is appropriate. Furthermore, this study shows that future research in spine surgery should be very critical in the evaluation of a so called favorable outcome and weigh this against the disadvantages in robust double blind randomized trials.

We thank the research nurses, the physicians who included patients, and the data manager of the SIPS group for their work in making this trial possible.

Nurses and data collection and management: M Nuyten, P Bergman, S Dukker, L Smakman (management), C Waanders, J Blom, J Videler, M de Raaf, M de Gooijer, J Vogelaar.

Participating hospitals and coordinating physicians: Medical Center Haaglanden, The Hague-M P Arts; Diaconessen Hospital, Leiden—R W Koot; Groene Hart Hospital, Gouda—J A L Wurzer; Spaarne Hospital, Hoofddorp-C L A M Vleggeert-Lankamp; Haga Hospital, The Hague-C F E Hoffmann; Rijnland Hospital, Leiderdorp-J H C Voormolen and M J T Verstegen; University Medical Center Utrecht-G J Amelink; Isala Klinieken Zwolle-F C de Beer; Vlietland Schiedam—R Walchenbach; Alkmaar Medical Center-W F Tan; Leiden University Medical Center, Leiden-W C Peul and J H C Voormolen;

Contributors: WAM, BWK, MPA, and WC P formed the Protocol Committee and were responsible for conception and design of the study. BWK, WAM, and WCP formed the Steering Committee. WAM, WCHJ, and EWvZ did the statistical analysis. WAM, WCP, CLAMV-L, MPA, and MEvdA-vM were involved in drafting and revising the manuscript. All authors approved the final version of the manuscript. WAM and WCP are the guarantors.

Funding: Paradigm Spine funded this trial. Paradigm Spine had no role in data collection, design of the study, data analysis, interpretation of data, or writing the report and had no influence over whether to submit the manuscript. All the researchers were individually independent from funders.

Competing interests: All authors have completed the ICMJE uniform disclosure form at www.icmje.org/coi_disclosure.pdf and declare that the FELIX trial was funded by Paradigm Spine/InSpine and was carried out by the Leiden-The Hague SIPS group; no financial relationships with any organizations that might have an interest in the submitted work in the previous three years; no other relationships or activities that could appear to have influenced the submitted work.

Ethical approval: The medical ethics committees at the 11 participating hospitals approved the protocol, including an approval for randomization after anesthetic induction. More information can be obtained from the central ethics committee at Leiden (decision letter P08.009). Written informed consent was obtained from all patients.

Data sharing: Technical appendix, statistical code, and dataset are available from the corresponding author at w.a.moojen@lumc.nl. Participants gave informed consent for data sharing.

Transparency declaration: The leading author (W C Peul) affirms that this manuscript is an honest, accurate, and transparent account of the study being reported; that no aspects of the study have been omitted; and that any discrepancies from the study as planned (and, if relevant registered) have been explained.

1 Park SC, Yoon SH, Hong YP, Kim KJ, Chung SK, Kim HJ. Minimum 2-year follow-up result of degenerative spinal stenosis treated with interspinous u (coflex). J Korean Neurosurg Soc 2009;46:292-9.

2 Deyo RA, Nachemson A, Mirza SK. Spinal-fusion surgery-the case for restraint. N Eng/ J Med 2004;350:722-6.

3 Deyo RA. Treatment of lumbar spinal stenosis: a balancing act. Spine J 2010;10:625-7. Van Tulder MW, Koes BW, Bouter LM. A cost-of-illness study of back pain in the Netherlands. Pain 1995;62:233-40.

5 Carragee EJ. The increasing morbidity of elective spinal stenosis surgery: is it necessary? JAMA 2010;303:1309-10.

6 Deyo RA, Mirza SK, Martin BI, Kreuter W, Goodman DC, Jarvik JG. Trends, major medical complications, and charges associated with surgery for lumbar spinal stenosis in older adults. JAMA 2010;303:1259-65.

7 Verbiest $\mathrm{H}$. A radicular syndrome from developmental narrowing of the lumbar vertebral canal. J Bone Joint Surg Br 1954;36-B:230-7.

$8 \quad$ Evans JG. Neurogenic intermittent claudication. BMJ 1964:2:985-7.

9 Ishimoto Y, Yoshimura N, Muraki S, Yamada H, Nagata K, Hashizume H, et al. Prevalence of symptomatic lumbar spinal stenosis and its association with physical performance in a population-based cohort in Japan: the Wakayama Spine Study. Osteoarthritis Cartilage 2012;20:1103-8.

10 Verbiest $\mathrm{H}$. [Primary stenosis of the lumbar spinal canal in adults, a new syndrome]. Ned Tijdschr Geneeskd 1950;94:2415-33.

11 Verbiest $\mathrm{H}$. [Further reports on primary stenosis of the lumbar spinal canal in adults]. Ned Tijdschr Geneeskd 1951;95:1965-70.

12 Johnsson KE, Uden A, Rosen I. The effect of decompression on the natural course of spinal stenosis: a comparison of surgically treated and untreated patients. Spine (Phila Pa 1976) 1991:16:615-9.

13 Malmivaara A, Slatis P, Heliovaara M, Sainio P, Kinnunen H, Kankare J, et al. Surgical or nonoperative treatment for lumbar spinal stenosis? A randomized controlled trial. Spine (Phila Pa 1976) 2007;32:1-8.

14 Weinstein JN, Tosteson TD, Lurie JD, Tosteson AN, Blood E, Hanscom B, et al. Surgical versus nonsurgical therapy for lumbar spinal stenosis. N Engl J Med 2008;358:794-810.

15 Turner JA, Ersek M, Herron L, Deyo R. Surgery for lumbar spinal stenosis: attempted meta-analysis of the literature. Spine (Phila Pa 1976) 1992;17:1-8.

16 Weinstein JN, Lurie JD, Tosteson TD, Hanscom B, Tosteson AN, Blood EA, et al. Surgical versus nonsurgical treatment for lumbar degenerative spondylolisthesis. N Engl J Med 2007;356:2257-70

17 Weinstein JN, Lurie JD, Tosteson TD, Zhao W, Blood EA, Tosteson AN, et al. Surgical compared with nonoperative treatment for lumbar degenerative spondylolisthesis: four-year results in the Spine Patient Outcomes Research Trial (SPORT) randomized and observational cohorts. J Bone Joint Surg Am 2009;91:1295-304.

18 Airaksinen O, Herno A, Kaukanen E, Saari T, Sihvonen T, Suomalainen O. Density of lumbar muscles 4 years after decompressive spinal surgery. Eur Spine $J$ 1996;5:193-7.

19 Hanraets PR. [Radicular syndrome and low-back pain]. Folia Psychiatr Neurol Neurochir Neerl 1953;56(1):3-20.

20 Fox MW, Onofrio BM, Onofrio BM, Hanssen AD. Clinical outcomes and radiological instability following decompressive lumbar laminectomy for degenerative spinal stenosis: a comparison of patients undergoing concomitant arthrodesis versus decompression alone. J Neurosurg 1996;85:793-802.

21 Fox MW, Onofrio BM. Indications for fusion following decompression for lumbar spinal stenosis. Neurosurg Focus 1997;3(2):e2.

22 Senegas J. [Surgery of the intervertebral ligaments, alternative to arthrodesis in the treatment of degenerative instabilities]. Acta Orthop Belg 1991;57(suppl 1):221-6.

23 Bartels RH. The X STOP device. J Neurosurg Spine 2007;6:620-1.

24 Chiu JC. Interspinous process decompression (IPD) system (X-STOP) for the treatment of lumbar spinal stenosis. Surg Technol Int 2006;15:265-75.

25 Eichholz KM, Fessler RG. Is the X STOP interspinous implant a safe and effective treatment for neurogenic intermittent claudication? Nat Clin Pract Neurol 2006:2:22-3.

26 Lee J, Hida K, Seki T, Iwasaki Y, Minoru A. An interspinous process distractor (X STOP) for lumbar spinal stenosis in elderly patients: preliminary experiences in 10 consecutive cases. J Spinal Disord Tech 2004;17:72-7.

27 Mariottini A, Pieri S, Giachi S, Carangelo B, Zalaffi A, Muzii FV, et al. Preliminary results of a soft novel lumbar intervertebral prothesis (DIAM) in the degenerative spinal pathology. Acta Neurochir Suppl 2005;92:129-31.

28 Oppenheimer JH, DeCastro I, McDonnell DE. Minimally invasive spine technology and minimally invasive spine surgery: a historical review. Neurosurg Focus 2009;27(3):E9.

29 Siddiqui M, Karadimas E, Nicol M, Smith FW, Wardlaw D. Effects of X-STOP device on sagittal lumbar spine kinematics in spinal stenosis. J Spinal Disord Tech 2006;19:328-33.

30 Sobottke R, Schluter-Brust K, Kaulhausen T, Rollinghoff M, Joswig B, Stutzer H, et al. Interspinous implants (X Stop, Wallis, Diam) for the treatment of LSS: is there a correlation between radiological parameters and clinical outcome? Eur Spine J 2009;18:1494-503. 


\section{What is already known on this topic}

Lumbar spinal stenosis is a common disease and is ranked fifth in terms of the costs of hospital care (owing to the increasing use of instruments)

After surgical intervention, $65 \%$ of patients with lumbar spinal stenosis have a favorable outcome

Bony decompression and treatment with interspinous process devices are superior to conservative and non-surgical treatment

\section{What this study adds}

At eight weeks and after one year, the success rate according to the Zurich Claudication Questionnaire for interspinous process device implantation was not superior to that for standard bony decompression

The repeat surgery rate in the interspinous implant group was $29 \%$, compared with $6 \%$ for the conventional group

31 Talwar V, Lindsey DP, Fredrick A, Hsu KY, Zucherman JF, Yerby SA. Insertion loads of the X STOP interspinous process distraction system designed to treat neurogenic intermittent claudication. Eur Spine J 2006;15:908-12.

32 Tsai KJ, Murakami H, Lowery GL, Hutton WC. A biomechanical evaluation of an interspinous device (Coflex) used to stabilize the lumbar spine. J Surg Orthop Adv 2006;15:167-72.

33 Wilke HJ, Drumm J, Haussler K, Mack C, Steudel WI, Kettler A. Biomechanical effect of different lumbar interspinous implants on flexibility and intradiscal pressure. Eur Spine $J$ 2008;17:1049-56.

34 Moojen WA, Arts MP, Bartels RH, Jacobs WC, Peul WC. Effectiveness of interspinous implant surgery in patients with intermittent neurogenic claudication: a systematic review and meta-analysis. Eur Spine J 2011;20:1596-606.

35 Zucherman JF, Hsu KY, Hartjen CA, Mehalic TF, Implicito DA, Martin MJ, et al. A prospective randomized multi-center study for the treatment of lumbar spinal stenosis with the X STOP interspinous implant: 1-year results. Eur Spine J 2004;13:22-31.

36 Zucherman JF, Hsu KY, Hartjen CA, Mehalic TF, Implicito DA, Martin MJ, et al. A multicenter, prospective, randomized trial evaluating the X STOP interspinous process decompression system for the treatment of neurogenic intermittent claudication: two-year follow-up results. Spine (Phila Pa 1976) 2005;30:1351-8.

37 Gibson JN, Waddell G, Grant IC. Surgery for degenerative lumbar spondylosis. Cochrane Database Syst Rev 2000;(2):CD001352.

38 Gibson JN, Waddell G. Surgery for degenerative lumbar spondylosis: updated Cochrane review. Spine (Phila Pa 1976) 2005;30:2312-20.

39 Thome C, Zevgaridis D, Leheta O, Bazner H, Pockler-Schoniger C, Wohrle J, et al. Outcome after less-invasive decompression of lumbar spinal stenosis: a randomized comparison of unilateral laminotomy, bilateral laminotomy, and laminectomy. J Neurosurg Spine 2005;3:129-41.

40 Kondrashov DG, Hannibal M, Hsu KY, Zucherman JF. Interspinous process decompression with the X-STOP device for lumbar spinal stenosis: a 4-year follow-up study. J Spinal Disord Tech 2006;19:323-7.

41 Verhoof OJ, Bron JL, Wapstra FH, van Royen BJ. High failure rate of the interspinous distraction device (X-Stop) for the treatment of lumbar spinal stenosis caused by degenerative spondylolisthesis. Eur Spine J 2008;17:188-92.

42 Moojen WA, Arts MP, Brand R, Koes BW, Peul WC. The Felix-trial: double-blind randomization of interspinous implant or bony decompression for treatment of spinal stenosis related intermittent neurogenic claudication. BMC Musculoskelet Disord 2010:11:100.

43 Pratt RK, Fairbank JC, Virr A. The reliability of the Shuttle Walking Test, the Swiss Spina Stenosis Questionnaire, the Oxford Spinal Stenosis Score, and the Oswestry Disability Index in the assessment of patients with lumbar spinal stenosis. Spine (Phila Pa 1976) 2002;27:84-91

44 Stucki G, Liang MH, Fossel AH, Katz JN. Relative responsiveness of condition-specific and generic health status measures in degenerative lumbar spinal stenosis. $J$ Clin Epidemiol 1995:48:1369-78

45 Stucki G, Daltroy L, Liang MH, Lipson SJ, Fossel AH, Katz JN. Measurement properties of a self-administered outcome measure in lumbar spinal stenosis. Spine (Phila Pa 1976) 1996;21:796-803

46 Tuli SK, Yerby SA, Katz JN. Methodological approaches to developing criteria for improvement in lumbar spinal stenosis surgery. Spine (Phila Pa 1976) 2006:31:1276-80.

47 Deyo RA, Diehl AK. Patient satisfaction with medical care for low-back pain. Spine (Phila Pa 1976) 1986:11:28-30.

48 Deyo RA, Patrick DL. The significance of treatment effects: the clinical perspective. Med Care 1995;33(4 suppl):AS286-91.

49 Hutchinson PJ, Laing RJ, Waran V, Hutchinson E, Hollingworth W. Assessing outcome in lumbar disc surgery using patient completed measures. Br J Neurosurg 2000;14:195-9.

50 Koes BW, van Tulder MW, Thomas S. Diagnosis and treatment of low back pain. BMJ 2006;332:1430-4.

51 Patrick DL, Deyo RA. Generic and disease-specific measures in assessing health status and quality of life. Med Care 1989;27(3 suppl):S217-32.

52 Patrick DL, Deyo RA, Atlas SJ, Singer DE, Chapin A, Keller RB. Assessing health-related quality of life in patients with sciatica. Spine (Phila Pa 1976) 1995;20:1899-908.

53 Roland M, Morris R. A study of the natural history of low-back pain. Part II: development of guidelines for trials of treatment in primary care. Spine (Phila Pa 1976) 1983:8:145-50.

54 Roland M, Morris R. A study of the natural history of back pain. Part I: development of a reliable and sensitive measure of disability in low-back pain. Spine (Phila Pa 1976) 1983;8:141-4.
55 Schoppink LE, van Tulder MW, Koes BW, Beurskens SA, de Bie RA. Reliability and validity of the Dutch adaptation of the Quebec Back Pain Disability Scale. Phys Ther 1996;76:268-75

56 Carlsson AM. Assessment of chronic pain. I: aspects of the reliability and validity of the visual analogue scale. Pain 1983;16:87-101.

57 Brazier JE, Harper R, Jones NM, O'Cathain A, Thomas KJ, Usherwood T, et al. Validating the SF-36 health survey questionnaire: new outcome measure for primary care. BMJ 1992;305:160-4.

58 McHorney CA, Ware JE Jr, Lu JF, Sherbourne CD. The MOS 36-item Short-Form Health Survey (SF-36). III: tests of data quality, scaling assumptions, and reliability across diverse patient groups. Med Care 1994;32:40-66.

59 Melzack R. The McGill Pain Questionnaire: major properties and scoring methods. Pain 1975;1:277-99.

60 Melzack $\mathrm{R}$. The McGill pain questionnaire: from description to measurement. Anesthesiology 2005;103:199-202.

61 Main CJ, Wood PL, Hollis S, Spanswick CC, Waddell G. The distress and risk assessment method: a simple patient classification to identify distress and evaluate the risk of poor outcome. Spine (Phila Pa 1976) 1992;17:42-52.

62 Singh SJ, Morgan MD, Scott S, Walters D, Hardman AE. Development of a shuttle walking test of disability in patients with chronic airways obstruction. Thorax 1992:47:1019-24.

63 Arts MP, Brand R, van den Akker ME, Koes BW, Bartels RH, Peul WC. Tubular diskectomy vs conventional microdiskectomy for sciatica: a randomized controlled trial. JAMA 2009;302:149-58.

64 Peul WC, Van Houwelingen HC, van den Hout WB, Brand R, Eekhof JA, Tans JT, et al. Surgery versus prolonged conservative treatment for sciatica. $N$ Engl J Med 2007:356:2245-56.

65 Bjelland I, Dahl AA, Haug TT, Neckelmann D. The validity of the Hospital Anxiety and Depression Scale: an updated literature review. J Psychosom Res 2002;52:69-77.

66 Rabe-Jablonska J, Bienkiewicz W. [Anxiety disorders in the fourth edition of the classification of mental disorders prepared by the American Psychiatric Association: diagnostic and statistical manual of mental disorders (DMS-IV—options book)]. Psychiatr Pol 1994;28:255-68.

67 Lønne G. Treatment of lumbar spinal stenosis; comparison of two different surgical methods; mini-invasive decompression to X-stop (LSSS). http://clinicaltrials.gov/show/ NCT00546949.

68 Davis RJ, Errico TJ, Bae H, Auerbach JD. Decompression and Coflex interlaminar stabilization compared with decompression and instrumented spinal fusion for spinal stenosis and low-grade degenerative spondylolisthesis: two-year results from the prospective randomized, multicenter, Food and Drug Administration Investigational Device Exemption trial. Spine (Phila Pa 1976) 2013;38:1529-39

69 Liu J, Liu H, Li T, Zeng J, Song Y, Liu L, et al. [A comparative study between Coflex interspinous dynamic reconstruction and lumbar 360 degrees fusion in treating single-leve degenerative lumbar spinal disorders]. Zhongguo Xiu Fu Chong Jian Wai Ke Za Zhi 2011;25:693-8.

70 Richter A, Schutz C, Hauck M, Halm H. Does an interspinous device (Coflex) improve the outcome of decompressive surgery in lumbar spinal stenosis? One-year follow up of a prospective case control study of 60 patients. Eur Spine $J$ 2010;19:283-9.

71 Richter A, Halm HF, Hauck M, Quante M. 2-year follow-up after decompressive surgery with and without implantation of an interspinous device for lumbar spinal stenosis: a prospective controlled study. J Spinal Disord Tech 2012; published online 4 May.

72 Stromqvist BH, Berg S, Gerdhem P, Johnsson R, Moller A, Sahlstrand T, et al. X-Stop versus decompressive surgery for lumbar neurogenic intermittent claudication: randomized controlled trial with 2-year follow-up. Spine (Phila Pa 1976) 2013;38:1436-42.

\section{Accepted: 07 October 2013}

\section{Cite this as: BMJ 2013:347:f6415}

This is an Open Access article distributed in accordance with the Creative Commons Attribution Non Commercial (CC BY-NC 3.0) license, which permits others to distribute, remix, adapt, build upon this work non-commercially, and license their derivative works on different terms, provided the original work is properly cited and the use is non-commercial. See: http://creativecommons.org/licenses/by-nc/3.0/. 


\section{Tables}

\section{Table 1/ Characteristics of patients at baseline. Values are numbers (percentages) unless stated otherwise}

\begin{tabular}{|c|c|c|}
\hline Characteristic & IPD group $(n=80)$ & Decompression group $(n=79)$ \\
\hline Median (range) age (years) & $66(45-83)$ & $64(47-83)$ \\
\hline Male sex & $49(61)$ & $37(47)$ \\
\hline $\begin{array}{l}\text { Median (range) duration of intermittent neurogenic claudication } \\
\text { (months) }\end{array}$ & $12(2-120)$ & $22(1-204)$ \\
\hline Median (range) body mass index* & $27(20-48)$ & $28(20-37)$ \\
\hline Duration of back pain (categorized) & $1-3$ years & $1-3$ years \\
\hline IPD patient's preferred treatment† & $39(49)$ & $36(46)$ \\
\hline Bony decompression patient's preferred treatment $†$ & $0(0)$ & $3(4)$ \\
\hline No preference for specific treatment $†$ & $41(51)$ & $40(50)$ \\
\hline Mild paresis or sensory loss & $54(67)$ & $56(71)$ \\
\hline \multicolumn{3}{|l|}{ Localization of stenosis: } \\
\hline L2-L3 & $2(3)$ & $3(4)$ \\
\hline L3-L4 & $25(31)$ & $22(28)$ \\
\hline L4-L5 & $53(66)$ & $54(68)$ \\
\hline Operated at two levels: & $21(26)$ & $16(20)$ \\
\hline L2-L3-L4 & $2(3)$ & $3(4)$ \\
\hline L2-L3 and L4-L5 & $1(1)$ & $0(0)$ \\
\hline L3-L4-L5 & $17(21)$ & $13(16)$ \\
\hline \multicolumn{3}{|l|}{ Zurich Claudication Questionnaireł: } \\
\hline Mean (SD) subscale symptom severity $0-5$ scaleł & $3.1(0.5)$ & $3.2(0.5)$ \\
\hline Mean (SD) subscale physical function 0-4 scaleł & $2.6(0.5)$ & $2.6(0.5)$ \\
\hline Mean (SD) Roland Disability Questionnaire 23 points & $13.0(5.2)$ & $14.4(4.5)$ \\
\hline Mean (SD) VAS leg pain $(\mathrm{mm}) \S$ & $52(24)$ & $58(24)$ \\
\hline Mean (SD) VAS back pain $(\mathrm{mm}) \S$ & $60(44)$ & $49(25)$ \\
\hline Median (range) SWT (m)ף & $180(20-1260)(n=70)$ & $140(10-1220)(n=70)$ \\
\hline Completed SWTף & $8(10)$ & $13(16)$ \\
\hline
\end{tabular}

IPD=interspinous process device; SWT=shuttle walking distance; VAS=visual analogue scale.

*Weight in kilograms divided by square of height in meters.

†Patients were asked if they had any treatment preference (no preference, IPD, or bony decompression).

$\ddagger$ Disease specific outcome score; at baseline, score was reported in two subdomains—symptom severity (range 0-5) and physical function (range 0-4).

§Intensity of pain was measured by horizontal $100 \mathrm{~mm}$ VAS, with 0 representing no pain and 100 worst pain ever.

IObtained before operation; patients were asked to walk until they got symptoms; test was scored "complete" when patients walked $1200 \mathrm{~m}$ in $15 \mathrm{~min}$ without stopping. 


\begin{tabular}{|c|c|c|c|c|c|c|c|c|c|c|c|c|c|c|}
\hline \multicolumn{15}{|c|}{ Table 2| Primary and secondary outcomes* } \\
\hline \multirow[b]{2}{*}{ Variable } & \multicolumn{2}{|c|}{$\begin{array}{c}\text { Baseline } \\
(n=159)\end{array}$} & \multicolumn{3}{|c|}{2 weeks $(n=129)$} & \multicolumn{3}{|c|}{8 weeks $(n=142)$} & \multicolumn{3}{|c|}{26 weeks $(n=141)$} & \multicolumn{3}{|c|}{52 weeks $(n=144)$} \\
\hline & IPD & BD & IPD & BD & & IPD & BD & & IPD & BD & & IPD & BD & \\
\hline $\begin{array}{l}\text { Primary } \\
\text { outcome }\end{array}$ & & & & & $\begin{array}{l}\text { OR }(P \\
\text { value) }\end{array}$ & & & $\begin{array}{l}\text { OR (P } \\
\text { value) }\end{array}$ & & & $\begin{array}{l}\text { OR }(P \\
\text { value) }\end{array}$ & & & $\begin{array}{l}\text { OR }(P \\
\text { value })\end{array}$ \\
\hline $\begin{array}{l}\%(95 \% \mathrm{Cl}) \\
\text { success } \\
\text { ZCQ }\end{array}$ & NA & NA & $\begin{array}{l}67(55 \\
\text { to } 77)\end{array}$ & $\begin{array}{l}57(45 \\
\text { to } 69)\end{array}$ & $\begin{array}{c}1.64 \\
(0.18)\end{array}$ & $\begin{array}{l}63(51 \\
\text { to } 73)\end{array}$ & $\begin{array}{l}72(60 \\
\text { to } 81)\end{array}$ & $\begin{array}{c}0.73 \\
(0.44)\end{array}$ & $\begin{array}{l}64(53 \\
\text { to } 74)\end{array}$ & $\begin{array}{l}63(50 \\
\text { to } 74)\end{array}$ & $\begin{array}{c}1.20 \\
(0.64)\end{array}$ & $\begin{array}{l}66(54 \\
\text { to } 74)\end{array}$ & $\begin{array}{l}69(57 \\
\text { to } 78)\end{array}$ & $\begin{array}{c}0.90 \\
(0.77)\end{array}$ \\
\hline $\begin{array}{l}\text { Secondary } \\
\text { outcomes }\end{array}$ & & & & & MD & & & MD & & & MD & & & MD \\
\hline $\begin{array}{l}\text { Mean (95\% } \\
\text { Cl) MRDQ } \\
\text { (23 points) } \\
\text { score }\end{array}$ & $\begin{array}{c}13.0 \\
(11.7 \text { to } \\
14.2)\end{array}$ & $\begin{array}{c}14.4 \\
(13.3 \text { to } \\
15.5)\end{array}$ & $\begin{array}{c}10.4 \\
(9.2 \text { to } \\
11.8)\end{array}$ & $\begin{array}{c}10.6 \\
(9.3 \text { to } \\
12.0)\end{array}$ & 0.1 & $\begin{array}{l}7.5(6.1 \\
\text { to } 9.0)\end{array}$ & $\begin{array}{l}6.5(5.3 \\
\text { to } 7.8)\end{array}$ & 1.0 & NA & NA & NA & $\begin{array}{l}6.9(5.4 \\
\text { to } 8.5)\end{array}$ & $\begin{array}{l}8.1(6.6 \\
\text { to } 9.7)\end{array}$ & $\begin{array}{c}1.2 \\
(0.28) \dagger\end{array}$ \\
\hline $\begin{array}{l}\text { Mean }(95 \% \\
\text { Cl) VAS } \\
\text { back pain } \\
(0-100 \mathrm{~mm})\end{array}$ & $\begin{array}{l}60(37 \\
\text { to } 83)\end{array}$ & $\begin{array}{l}49(44 \\
\text { to56) }\end{array}$ & $\begin{array}{l}32(27 \\
\text { to38) }\end{array}$ & $\begin{array}{l}33(28 \\
\text { to39) }\end{array}$ & 1 & $\begin{array}{l}24(19 \\
\text { to } 30)\end{array}$ & $\begin{array}{l}23(17 \\
\text { to } 28)\end{array}$ & 1 & NA & NA & NA & $\begin{array}{l}23(17 \\
\text { to } 29)\end{array}$ & $\begin{array}{l}31(24 \\
\text { to } 37)\end{array}$ & $\begin{array}{c}8 \\
(0.09) \dagger\end{array}$ \\
\hline \multirow[t]{2}{*}{$\begin{array}{l}\text { Mean }(95 \% \\
\text { Cl) VAS leg } \\
\text { pain }(0-100 \\
m m)\end{array}$} & $\begin{array}{l}52(47 \\
\text { to } 59)\end{array}$ & $\begin{array}{l}58(52 \\
\text { to } 64)\end{array}$ & $\begin{array}{l}23(18 \\
\text { to } 28)\end{array}$ & $\begin{array}{l}26(20 \\
\text { to } 32)\end{array}$ & 3 & $\begin{array}{l}26(20 \\
\text { to } 32)\end{array}$ & $\begin{array}{l}22(18 \\
\text { to } 27)\end{array}$ & 4 & NA & NA & NA & $\begin{array}{l}23(17 \\
\text { to } 30)\end{array}$ & $\begin{array}{l}26(20 \\
\text { to } 33)\end{array}$ & $\begin{array}{c}3 \\
(0.54) \dagger\end{array}$ \\
\hline & & & & & & & & $\begin{array}{l}\text { OR ( } P \\
\text { value) }\end{array}$ & & & & & & $\begin{array}{l}\text { OR (P } \\
\text { value) }\end{array}$ \\
\hline $\begin{array}{l}\text { Mean (95\% } \\
\text { Cl) Likert \% } \\
\text { perceived } \\
\text { successł }\end{array}$ & NA & NA & NA & NA & NA & $\begin{array}{l}51(40 \\
\text { to } 63)\end{array}$ & $\begin{array}{l}53(41 \\
\text { to } 64)\end{array}$ & $\begin{array}{c}0.94 \\
(0.85)\end{array}$ & NA & NA & NA & $\begin{array}{l}56(45 \\
\text { to } 67)\end{array}$ & $\begin{array}{l}49(38 \\
\text { to } 60)\end{array}$ & $\begin{array}{l}1.37 \\
(0.37)\end{array}$ \\
\hline
\end{tabular}

$\mathrm{BD}=$ bony decompression; IPD=interspinous process device; $\mathrm{MD}=$ mean difference; $\mathrm{MRDQ}=$ modified Roland Disability Questionnaire; $\mathrm{NA}=$ test not administered; $\mathrm{OR}=$ odds ratio; $\mathrm{VAS}=$ visual analogue scale; $\mathrm{ZCQ}=\mathrm{Zurich}$ Claudication Questionnaire.

*Outcomes were analyzed with generalized estimating equations (GEE). Outcome was reported as odds ratio for better success rate when treated with IPD versus bony decompression and overall P value (based on GEE) of interaction between two groups based on continuous outcome scales with mean differences (MRDQ and VAS).

†Overall score in continuous outcome scales were not significant (MRDQ and VAS).

‡Likert global perceived recovery defined by 7 point scale from "worse" to "complete" recovery; score was dichotomized between good recovery (1-2) and bad recovery (3-7). 
Table 3| Secondary outcomes at 8 and 52 weeks*

\begin{tabular}{|c|c|c|c|}
\hline Outcome & IPD & Decompression & Odds ratio $(P$ value) \\
\hline \multicolumn{4}{|l|}{$\%$ success $(95 \% \mathrm{Cl})$ on shuttle walking test: } \\
\hline 8 weeks (increase of $80 \mathrm{~m}$ or complete) & $57(0.45$ to 0.68$)(n=73)$ & $59(0.47$ to 0.88$)(n=72)$ & $0.75(0.33)$ \\
\hline 52 weeks (increase of $80 \mathrm{~m}$ or complete) & $57(0.43$ to 0.69$)(n=66)$ & $51(0.40$ to 0.62$)(n=70)$ & $1.25(0.54)$ \\
\hline \multicolumn{4}{|l|}{ Mean $(95 \% \mathrm{Cl})$ SF-36 score: } \\
\hline Bodily pain 8 weeks & 66 (61 to 71$)$ & 63 (58 to 68 ) & $(0.40) \ddagger$ \\
\hline Bodily pain 52 weeks & 66 (60 to 72$)$ & 62 (57 to 68$)$ & \\
\hline Physical functioning 8 weeks & 64 (59 to 70$)$ & 67 (62 to 72$)$ & $(0.72) \ddagger$ \\
\hline Physical functioning 52 weeks & 63 (58 to 69$)$ & 62 (56 to 68$)$ & \\
\hline Social functioning 8 weeks & $74(69$ to 80$)$ & 76 (70 to 82$)$ & $(0.95) \ddagger$ \\
\hline Social functioning 52 weeks & 77 (70 to 83 ) & 77 (72 to 82 ) & \\
\hline Physical role 8 weeks & 44 (34 to 54$)$ & 42 (33 to 51 ) & $(0.96) \ddagger$ \\
\hline Physical role 52 weeks & 55 (45 to 65$)$ & 55 (46 to 65$)$ & \\
\hline Emotional role 8 weeks & 74 (65 to 83 ) & 80 (72 to 88$)$ & $(0.46) \ddagger$ \\
\hline Emotional role 52 weeks & $74(65$ to 83$)$ & $79(71$ to 87$)$ & \\
\hline Mental health index 8 weeks & 77 (73 to 81$)$ & 76 (72 to 80$)$ & $(0.92) \ddagger$ \\
\hline Mental health index 52 weeks & 75 (70 to 80$)$ & 75 (71 to 79$)$ & \\
\hline Vitality 8 weeks & 64 (60 to 68$)$ & 62 (58 to 67$)$ & $(0.60) \ddagger$ \\
\hline Vitality 52 weeks & 61 (56 to 66$)$ & 59 (55 to 64$)$ & \\
\hline General health perception 8 weeks & 67 (63 to 71$)$ & 63 (59 to 67$)$ & $(0.34) \ddagger$ \\
\hline General health perception 52 weeks & $62(57$ to 67$)$ & 59 (55 to 63$)$ & \\
\hline \multicolumn{4}{|l|}{ Mean $(95 \% \mathrm{Cl}$ ) McGill Pain Questionnaire (0-78 points): } \\
\hline 8 weeks & 11 (9 to 12$)$ & 10 (8 to 12$)$ & \\
\hline 52 weeks & $11(9$ to 13$)$ & 10 (9 to 12$)$ & $(0.70) \ddagger$ \\
\hline \multicolumn{4}{|l|}{ Median (range) HADS depression score§: } \\
\hline Baseline & $4(0-9)$ & $3(1-9)$ & \\
\hline 52 weeks & $3(0-9)$ & $3(0-9)$ & \\
\hline \multicolumn{4}{|l|}{ Median (range) HADS anxiety score§: } \\
\hline Baseline & $7(2-14)$ & $6(2-12)$ & \\
\hline 52 weeks & $6(1-12)$ & $6(0-14)$ & \\
\hline No (\%) reoperations & $21(29)$ & $6(8 \%)$ & $(<0.001) \S$ \\
\hline No (\%) ZCQ success of reoperated patients & $10(48)$ & $3(50)$ & \\
\hline No (\%) operated at two levels & $21(26)$ & $16(18)$ & \\
\hline No of reoperations in patients operated at two levels & 8 & 1 & $(0.03) \S$ \\
\hline$\%(95 \% \mathrm{Cl}) \mathrm{ZCQ}$ success at 8 weeks & 67 (45 to 83 ) & 48 (24 to 73 ) & $2.50(0.06)$ \\
\hline$\%(95 \% \mathrm{Cl}) \mathrm{ZCQ}$ success at 52 weeks & $49(29$ to 69$)$ & $53(25$ to 79$)$ & $0.83(0.83)$ \\
\hline Mean $(95 \% \mathrm{Cl})$ duration of operation $(\mathrm{min})$ & 24 (22 to 26$)$ & 43 (39 to 47 ) & $(<0.001)^{\star *}$ \\
\hline Blood loss (mL)—categorized & $10-50$ & $50-100$ & $(<0.001)^{\star *}$ \\
\hline Complications during hospital stay & 5 & 6 & \\
\hline Spinous process fractures & 3 & †† & †† \\
\hline Mean (SD) hospital stay & $1.83(0.9)$ & $1.89(1.2)$ & $(0.753)^{\star \star}$ \\
\hline No (\%) blinded to allocated treatment & $54(67)$ & $68(86)$ & \\
\hline
\end{tabular}

HADS=Hospital Anxiety and Depression Scale; IPD=interspinous process device; ZCQ=Zurich Claudication Questionnaire.

*Outcomes were analyzed with generalized estimating equations (GEE).

†Odds ratio for better success rate when treated with IPD versus bony decompression, based on GEE.

‡Overall $P$ value (based on GEE) of interaction between two groups based on continuous outcome scale (SF-36 and McGill).

$\S S$ core consists of sum score of 7 item ( $0-3$ points per item) questionnaire ranging from 0 to 21 points; HADS-anxiety $>8$ is suspect for generalized anxiety disorder; HADS-depression $>8$ is suspect for depression.

I0-10 mL, 10-50 mL, 50-100 mL, 100-200 mL.

${ }^{* *} P$ value with Fisher's exact test and Pearson $x^{2}$. 


\section{Table 3 (continued)}

††Spinous process fractures were not registered as relevant complications in bony decompression group, so no comparison (or $\mathrm{P}$ value). 


\section{Figures}

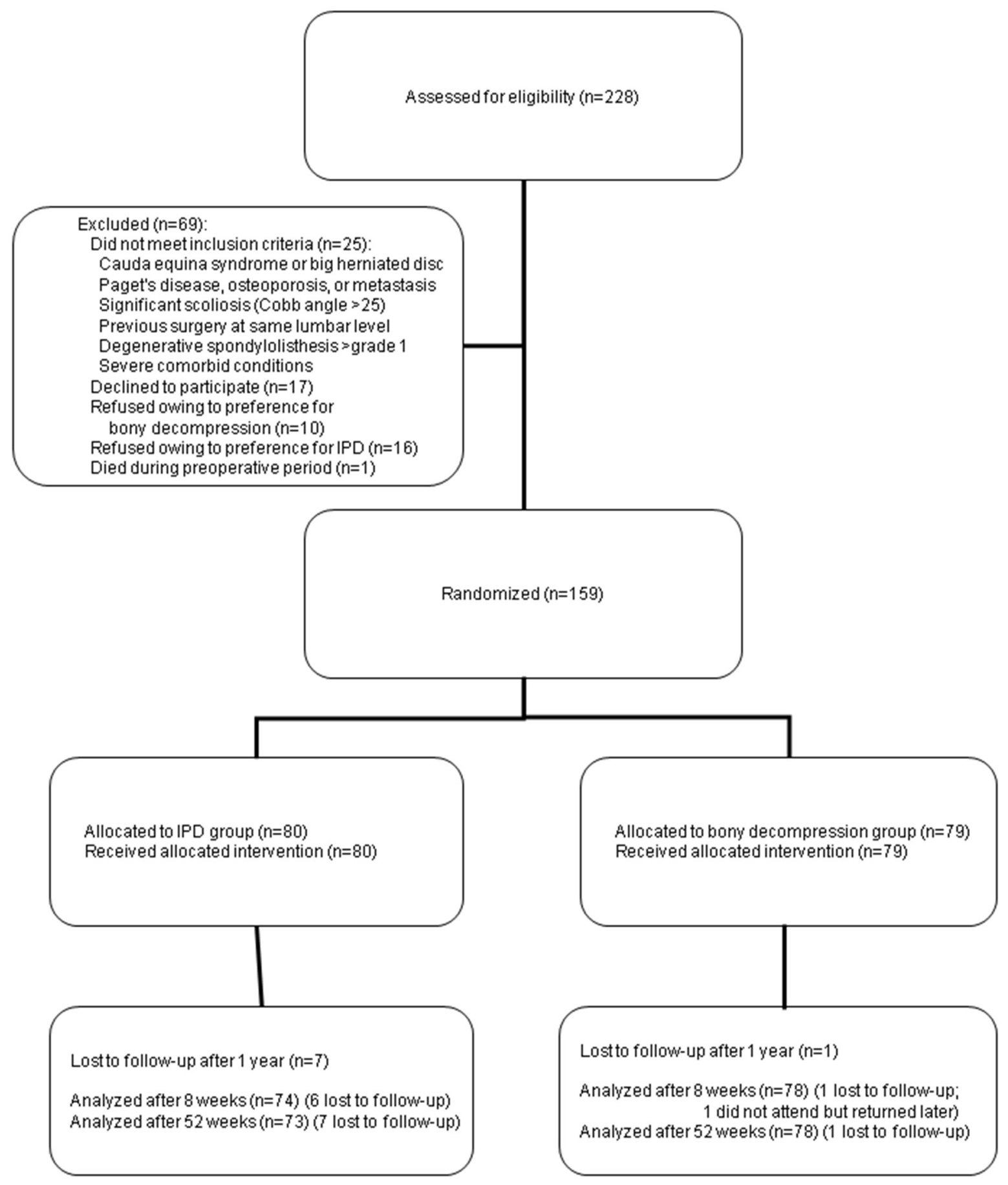

Fig 1 Flow chart of enrollment and follow-up. IPD=interspinous process device 

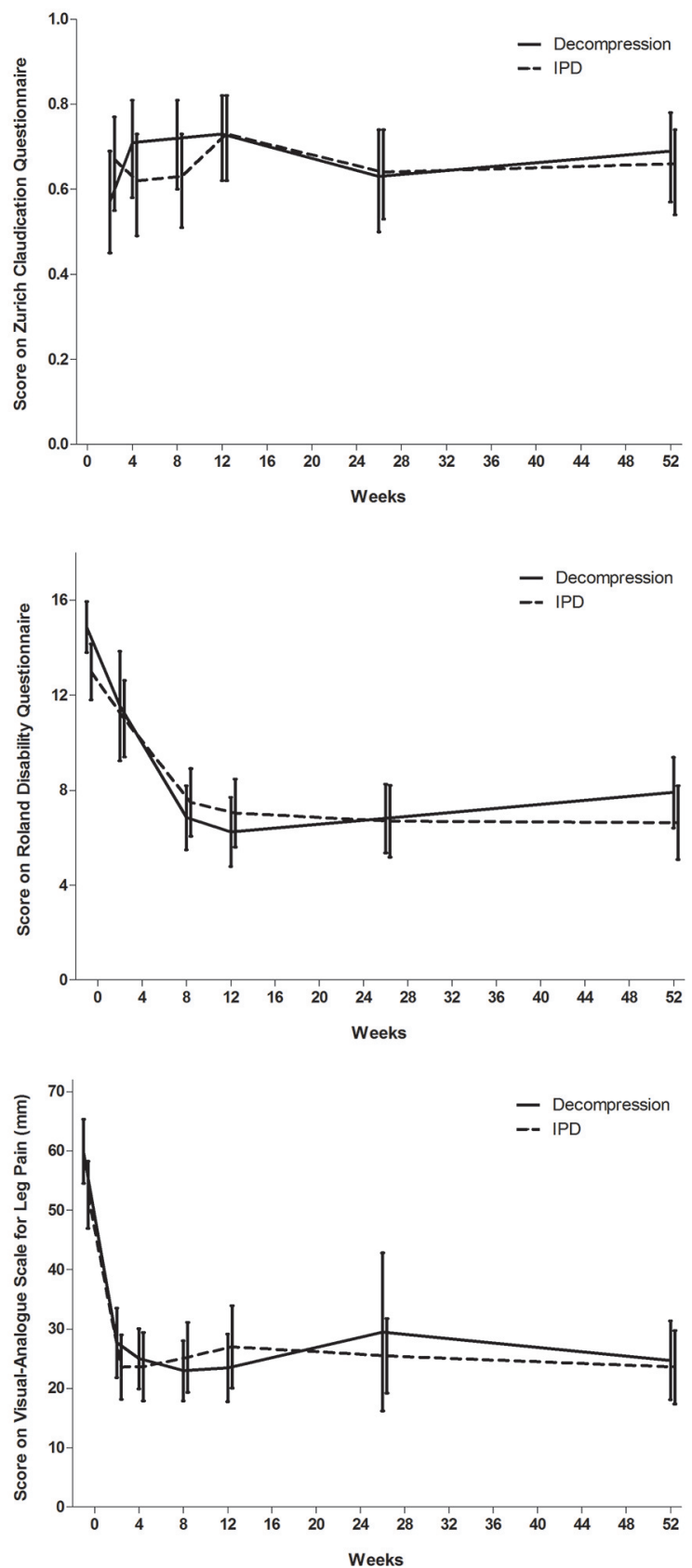

Fig 2 Scores on Zurich Claudication Questionnaire (top), modified Roland Disability Questionnaire (middle), and visual analogue scale (bottom) in two groups during follow-up. IPD=interspinous process device 